\title{
A proteção de nascentes para conservação dos recursos hídricos em atenção à nova lei florestal
}

\author{
Kamila Lemos Costa Barros ${ }^{1}$, Marcondes Geraldo Coelho Junior ${ }^{1}, *$, \\ Athila Leandro de Oliveira ${ }^{1}$, Vanessa Cabral Costa de Barros ${ }^{2}$, \\ Vanessa Maria Basso ${ }^{3}$, Acacio Geraldo de Carvalho ${ }^{4}$
}

${ }^{1}$ Programa de Pós-Graduação em Ciências Ambientais e Florestais, Universidade Federal Rural do Rio de Janeiro. BR-465, km 7, s/no. Seropédica-RJ, Brasil (CEP 23897-000). *E-mail: marcondescoelho22@gmail.com.

${ }^{2}$ Programa de Pós-Graduação em Engenharia Florestal. Universidade Federal de Lavras. Campus Universitário, Lavras-MG, Brasil (CEP 37200-000).

${ }^{3}$ Universidade Federal Rural do Rio de Janeiro. Instituto de Florestas. Departamento de Silvicultura. BR-465, km 7, s/nํ․ Seropédica-RJ, Brasil (CEP 23897-000)

${ }^{4}$ Universidade Federal Rural do Rio de Janeiro. Instituto de Produtos Florestais. Departamento de Silvicultura. BR-465, km 7, s/no. Seropédica-RJ, Brasil (CEP 23897-000).

Resumo. Em 2012, foi publicada a nova lei florestal brasileira. Por meio dela, as nascentes tiveram suas formas de proteção modificadas, permitindo a continuidade de determinadas ações em área de preservação permanente com ocupação antrópica anterior a 22 de julho de 2008, considerada área rural consolidada. Com o objetivo de questionar implicações que as Áreas Rurais Consolidadas possam trazer para a provisão de água, foi realizada uma revisão crítica da literatura à luz da problematização entre os avanços e retrocessos trazidos pela Lei no 12.651/2012, às unidades da paisagem e seus serviços ambientais, evidenciando o modo como as nascentes são afetadas. 0 estudo apontou que as mudanças na legislação colocaram em risco a manutenção de funções eco-hidrológicas. Por isso a relevância do assunto, para subsidiar ações prudentes a fim de vigorar a importância ambiental das áreas prejudicadas.

Palavras-chave: Área de preservação permanente; Área rural consolidada; Política ambiental; Vegetação nativa; Serviços ecossistêmicos.

Abstract. Protection of water springs to conserve water resources in accordance with the new forest law. The new Brazilian Forestry Law was published in 2012. Through which, the springs had their forms of protection modified, allowing the continuity of certain actions in permanent preservation areas with anthropic occupation prior to July 22, 2008, which were considered as consolidated rural areas. In order to raise questions on the implications that consolidated rural areas can

Recebido: $06 / 05 / 2018$

Aceito: 10/08/2018

Publicado: $31 / 08 / 2018$

Acesso aberto

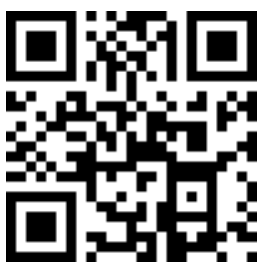

ORCID

(ㄷ) 0000-0002-7541-0958

Kamila Lemos Costa

Barros

D 0000-0002-4352-9321

Marcondes Geraldo

Coelho Junior 
generate to water supply, a critical review of the literature was carried out based on the problematization between the advances and retrocessions brought by Law No. 12.651/2012, which influence the landscape units and their environmental services, evidencing the way the springs are affected. This study pointed out that changes in legislation put at risk the maintenance of ecohydrological functions. Therefore, it is relevant to subsidize prudent actions to strengthen the environmental importance of damaged areas.

Keywords: Permanent preservation area; Consolidated rural areas, Environmental politics, Native vegetation, Ecosystem services.

\section{Introdução}

A água é um recurso básico para todo ser vivo. Porém, a população humana não desfruta do uso da água de maneira igualitária. E além disso, o consumo tem aumentado: agropecuário ou industrial, rural ou urbano. Contudo, devido às tecnologias e maior cobrança por um consumo sustentável, tem-se postergado uma crise mundial (Tundisi e Matsumura-Tundisi, 2011).

A água é também um dos principais fatores na avaliação e custo da terra. Ainda assim, apesar de estar inserida em todos os seus custos e ser determinante para sua produtividade, nem sempre os proprietários dos imóveis têm consciência da importância das ações de conservação das nascentes (Soares-Filho et al., 2014). Obrigação reconhecida por lei no Brasil, com embasamento técnico e científico, pois favorecem o afloramento do lençol freático (Brasil, 2012).

Baker e Miller (2013) salientam que a redução de cobertura florestal pode ter sérias implicações para os recursos hídricos, pois a interceptação de água da chuva é diminuída e as taxas de infiltração no solo podem ser excedidas. Dessa forma, a água que poderia compor o lençol freático passa a escoar superficialmente, o que implica em menor formação de nascente, e muitas vezes aumento nas taxas de erosão dos solos.
(D) 0000-0002-9455-8237

Athila Leandro de

Oliveira

(D) 0000-0002-0003-4599

Vanessa Cabral Costa

de Barros

(D) 0000-0003-3141-2262

Vanessa Maria Basso

(D) 0000-0002-0935-7773

Acacio Geraldo de

Carvalho
0 crescimento e melhoria técnica do agronegócio é realidade para diversas culturas brasileiras, atingindo médias superiores a níveis mundiais (Lapola et al., 2014). Sabendo da possibilidade do crescimento do uso de tecnologias sustentáveis e otimização do uso da terra, torna-se assim, incoerente a redução da área de proteção do entorno de nascente, por qualquer que seja o motivo.

Questiona-se neste artigo a possibilidade de se dar continuidade ao uso antrópico dentro de áreas consideradas de preservação permanente, em especial no entorno de nascentes, flexibilidade trazida pelo novíssimo Código Florestal, Lei no 12.651/2012 (Brasil, 2012), e demais regulamentações. Tendo isso em vista, os tópicos a seguir propõem-se conceituar o objeto de estudo, as nascentes, caracterizar as mudanças no que tange a este objeto como elemento da paisagem, destacando a importância destas e demais áreas que possam ter influência sobre o afloramento do lençol freático, bem como elementos da legislação vigente.

O objetivo do presente artigo foi realizar uma revisão crítica da literatura, questionando a possibilidade de continuar o uso antrópico das áreas consideradas de preservação permanente, em especial em torno de nascentes, flexibilidade trazida pelo Novíssimo Código Florestal (Brasil, 2012). Tendo isso em vista, os tópicos a seguir propõem-se conceituar o objeto de 
estudo, as nascentes, caracterizar as mudanças no que tange a este objeto como elemento da paisagem, destacando a importância destas e demais áreas que possam ter influência sobre 0 afloramento do lençol freático, bem como elementos da legislação vigente.

\section{As nascentes}

Da década de 1960, por Davis (1966), tem-se o conceito de nascente como qualquer descarga superficial de água, grande o suficiente para fluir em um pequeno arroio. Já trazendo para os anos 2000, a conceituação de nascente não é única e dificulta a sua aplicação, como por exemplo, no cumprimento da legislação pelos órgãos ambientais nas esferas federal, estadual e municipal, para regular as atividades que se direcionam em áreas onde essas estão presentes.

Utilizando-se do termo "fonte", Guerra e Guerra (2009) definiram as nascentes como um manancial de água que resulta da infiltração das águas nas camadas permeáveis e o uso desse termo no plural, "fontes", como sinônimo de cabeceira de um rio, correspondendo a uma área onde existem os olhos d'água que dão origem a um curso fluvial. Essas fontes seriam então, para os mesmos autores, os lugares onde brotam ou nascem as águas.

Castro e Gomes (2001) expuseram que as nascentes podem ser classificadas segundo o regime de água ou o tipo de reservatório a que estão associadas. São ditas perenes, quando as nascentes apresentarem um fluxo de água contínuo e constante, inclusive na estação seca. Já quando apresentarem fluxo de água somente durante a estação das chuvas, são classificadas como temporárias. Quando durante uma chuva surgir uma nascente, e esta permanecer apenas por alguns dias e logo depois desaparecer, é denominada como nascente efêmera.
No campo da geomorfologia, Kresic e Stevanovic (2009) fizeram uma abordagem específica sobre a caracterização de tipos de nascentes, como podem ser mencionadas, as nascentes difusas, de fissura, secundárias, termais, submersas e, até mesmo, as intermitentes. Queiroz (2015), citando tais autores, dispôs que estes consideraram que todas as nascentes têm exsudação à superfície devido à força da gravidade, exceto algumas associadas a vulcanismo recente e atividade hidrotermal. Em outra perspectiva, ainda pode-se considerar as nascentes que são originadas pelas ações humanas, mencionadas por Felippe et al. (2013), como nascentes antropogênicas. O mesmo autor comenta que o homem pode promover ou intensificar os processos geomorfológicos que culminam na exfiltração da água subterrânea em locais onde, naturalmente, não ocorreria e quando esses fluxos entram em contato com a rede de drenagem, se tem a gênese dessas nascentes.

Do ponto de vista legal, independente da caracterização atribuída à nascente, o conceito é entendido pela Lei $\mathrm{n}$ o $12.651 / 2012$, em seu art. 3을 como "afloramento natural do lençol freático que apresenta perenidade e dá início a um curso d'água". Já olhos d'água, a mesma lei tratou de forma diferente em relação a lei anterior, como: "afloramento natural do lençol freático, mesmo que intermitente" (Brasil, 2012).

Diante desses vocábulos, que ora se apresentam ainda de outras formas em função do regionalismo, Queiroz (2015) trouxe como produto de uma revisão conceitual de nascentes, uma síntese (Tabela 1), para facilitar a compreensão.

Em vista disto, considerar-se-á neste estudo as definições de nascente e olho d'água tal qual definida pela legislação vigente, Lei no 12.651/2012 (Brasil, 2012). 
Tabela 1. Proposta conceitual sobre fontes de água.

\begin{tabular}{ll}
\hline & Conceito \\
\hline \multirow{2}{*}{ Nascente } & $\begin{array}{l}\text { Local de descarga natural da água subterrânea na superfície do terreno que } \\
\text { gera fluxo visível. Localiza-se na base da cabeceira, ou seja, é o ponto de } \\
\text { superfície potencial mínima ao longo de um ciclo hidrológico anual (seja } \\
\text { bimodal, com períodos seco e chuvoso, ou monomodal, com chuvas bem } \\
\text { distribuídas ao longo do ano). }\end{array}$ \\
\hline Olho d'água & $\begin{array}{l}\text { Local de descarga natural da água subterrânea na superfície do terreno que } \\
\text { pode ou não gerar fluxo visível e que pode ser sazonal ou perene, com base } \\
\text { em um ciclo hidrológico anual. Considera-se, individual ou coletivamente, } \\
\text { como área úmida. }\end{array}$ \\
\hline Cabeceira & $\begin{array}{l}\text { Conjunto de nascentes e olhos d'água que compõe o alto curso da bacia } \\
\text { hidrográfica. }\end{array}$ \\
\hline Fonte & $\begin{array}{l}\text { Nascentes, olhos d'água ou mecanismos de captação de água subterrânea } \\
\text { para consumo humano. }\end{array}$ \\
\hline
\end{tabular}

Fonte: Adaptado de Queiroz (2015).

\section{Proteção às nascentes}

É notório que onde exista floresta, os atributos do meio ambiente se apresentem em estado de melhores condições do que em lugar degradado. A presença de florestas nativas pode desempenhar diversas funções eco e hidrológicas, como a regulação da quantidade de água, o controle da erosão e aporte de sedimentos e, consequentemente, influenciando os parâmetros físico-químicos dos cursos d'água (Lima et al., 2013).

As florestas possuem relação estreita com a provisão e disponibilidade de água de boa qualidade e em quantidade suficiente à manutenção dos ciclos ecológicos, como visto por Pereira et al. (2016), ao estudarem as florestas de altitude situadas nas microbacias da Serra do Mar, no Estado do Rio de Janeiro, concluindo que estas contribuem para suprir a demanda de água pela população fluminense.

A proteção aos serviços ecossistêmicos garante a produção e despoluição da água, portanto, é essencial para vida humana (LamimGuedes et al., 2017). Sob essa mesma percepção, Tundisi e Matsumura-Tundisi (2008) ressaltam haver evidências científicas relevantes sobre o efeito de vegetação na regulação do ciclo hidrológico.

Pelas razões anteriormente apontadas, e conforme o reconhecimento da Constituição Federal as florestas e as demais formas de vegetação são um bem público, isto é, o meio ambiente pertence a todos e cabe à coletividade, não só ao Estado, garantir um ambiente equilibrado (Brasil, 1988).

$\mathrm{Na}$ conjuntura legal, medidas para proteção de áreas naturais surgiram desde o Código Florestal de 1934 (Brasil, 1934). Neste mesmo ano, pelo Decreto $n^{-}$ 23.793/1934, segundo Medeiros (2006), se teve a regulamentação do conceito de Florestas Protetoras, que tinha a função similar a atual APP, e também sobre a Reserva Legal (RL). Para a época em que foi criado, o Código Florestal pode ser considerado como conservacionista (Magalhães, 2002).

0 Decreto no 23.793/1934 é

considerado o primeiro "Código Florestal" brasileiro (Brasil, 1934). Mas, foi mais tarde, com a Lei no 4.771/1965, que houve uma maior restrição sobre as ações permitidas em áreas de florestas, ou zonas específicas, definidas posteriormente, como APP. Machado (2004) anunciou esta lei como a precursora da Constituição Federal de 
1988 (Brasil, 1988) por conceituar meio ambiente como um bem de uso comum do povo brasileiro.

A atual Lei Florestal, estabelecida por meio da Lei no 12.651/2012, conceitua APP em seu art. 3o, inciso II:

área protegida, coberta ou não por vegetação nativa, com a função ambiental de preservar os recursos hídricos, a paisagem, a estabilidade geológica e a biodiversidade, facilitar o fluxo gênico de fauna e flora, proteger o solo e assegurar o bemestar das populações humanas (Brasil, 2012).

Esta definição é semelhante a que constava no art. $1^{\circ}, \S 2^{\circ}$, inciso II, da Lei no 4.771/1965, do Código Florestal (Brasil, 1965).

Particularizando sobre a APP de nascentes, pelo arcabouço legal, as áreas de nascentes são locais que atuam diretamente na manutenção da qualidade e quantidade de água. Agem sobre os mecanismos de recarga do lençol freático, sobre a regulação térmica da água, possibilitam maior pureza, filtragem dos escoamentos, ora contaminados por resíduos químicos de práticas agrícolas, regulam fluxos de sedimentos e nutrientes, bem como proporcionam melhores condições para espécies da fauna e flora (Silva et al., 2008; Borges et al., 2011).

A ausência de matas ciliares no entorno de nascentes proporciona maior aquecimento das águas e já o sombreamento dos cursos d'água, pela vegetação, resulta na qualidade de água favorável a macro e microfauna, conforme evidenciado por Pinto et al. (2012), ao avaliar qualitativamente nascentes com seu entorno coberto apenas por pastagem.

A qualidade da água de uma nascente pode ser diversa. Fundamentalmente, essa qualidade depende de fatores originados pela precipitação, condições de solos e geologia da bacia de drenagem e atividades humanas realizadas nas áreas em torno (Arantes et al., 2012). Rodrigues-Filho et al. (2015) em um estudo que avaliaram diferentes usos do solo em uma bacia hidrográfica, evidenciaram que os mosaicos de vegetação nativa mantêm elevadas concentrações de fósforo e nitrogênio e possibilitam uma rápida reciclagem biogeoquímica que impede o transporte desses nutrientes até os baixos níveis presentes num sistema aquático. Com a remoção ou ausência de vegetação nesses locais ou ainda a substituição dessas áreas por culturas agrícolas, ocorrem aumentos de cargas de nutrientes e no estado trófico dos corpos d'água, podendo comprometer a recarga das águas subterrâneas e das nascentes.

Dada a importância dos aspectos técnicos tratados anteriormente, as políticas nacionais têm pautado a cobertura vegetal no entorno desses mananciais e a qualidade da água. A Lei no 9.433/1997 (Brasil, 1997), que institui a Política Nacional dos Recursos Hídricos (PNRH), vigente, reafirma a proteção de APPs, fundamentando-se no fato de que a água, embora reconhecida como um recurso natural renovável é também considerada um recurso natural limitado, dotado de valor econômico e de domínio público.

0 art. 4ํㅜ inciso IV, da Lei $\mathrm{n}^{\mathrm{o}}$ 12.651/2012, estabelece como áreas protegidas, ou simplesmente APP, aquelas em torno das nascentes e dos olhos d'água perenes, qualquer que seja sua situação topográfica, em um raio mínimo de $50 \mathrm{~m}$ (Brasil, 2012). No entanto, a definição da metragem das faixas de APPs baseadas apenas nas larguras do rio é considerada incompleta, sendo indicado o uso de outros critérios como índices pluviométricos e morfologia da região ou da bacia hidrográfica para sua real delimitação considerando as particularidades regionais (Metzger, 2010; Leitão et al, 2017).

Em função das diversidades climáticas, geológicas, pedológicas e biológicas do território brasileiro, 
mencionadas pela Sociedade Brasileira para o Progresso da Ciência (SBPC, 2011), reitera-se que são encontrados vários tipos de APPs: topo de morro, curso de água, lagos e lagoas naturais, algumas de encostas, restingas, manguezais, de bordas dos tabuleiros, das veredas, e como já mencionado, também no entorno de nascentes e olhos d'água perenes (Brasil, 2012). Essas APPs, mesmo que não se encontrem interligadas fisicamente, prestam serviços ambientais em seu conjunto.

A SBPC (2011) reconhece que algumas características chaves deveriam ser consideradas no processo de fixação de uma APP, entre elas a profundidade do lençol freático, a textura e espessura dos solos e as declividades das encostas adjacentes aos cursos d'água, além da suficiência de vegetação, para que sejam garantidos o fluxo gênico de espécies e a conservação da biodiversidade. Metzger (2010) ainda ressalta que a largura mínima deve priorizar a função mais exigente.

Por isso, em uma perspectiva endógena, não há eficiência em gestão das águas, isto é, em políticas e ações a partir da setorização da área de acordo com as vocações hidrológicas, objetivando-se a perenidade dos recursos hídricos, sem considerar a sustentabilidade estratégica a partir das comunidades, especialmente as rurais. 0 que é consoante ao explicitado por Borges (2008), que é preciso realçar a inter-relação homem-meio ambiente.

$\mathrm{Na}$ prática, observa-se uma relação intrínseca entre o econômico e o ecológico. Ambos estão também correlacionados aos critérios físicos, ao proteger a paisagem e seus processos, e psicológicos, ao favorecer as relações do indivíduo com o seu meio, chegando a função cultural dessa proteção ambiental (Fisher e Sá, 2007). Assim, a proteção nem sempre é uma prioridade aos produtores rurais, visto não visualizam que as diversas áreas de proteção podem atuar de forma conjunta na disponibilidade de água da propriedade.

\section{Alterações nos instrumentos de proteção às nascentes}

Tambosi et al. (2015), observaram que houve redução na extensão de vegetação nativa a ser conservada em propriedades privadas, a partir na nova Lei Florestal. Para Tundisi (2014), as alterações no Código Florestal Brasileiro podem produzir grandes modificações na qualidade e na quantidade de recursos hídricos.

Nos últimos seis anos, desde a promulgação da lei que substituiu o antigo Código Florestal Brasileiro, a alterações decorrentes dessa mudança na legislação, criaram um cenário inseguro do ponto de vista da conservação dos recursos hídricos. Na Resolução no 303/2002, do Conselho Nacional de Meio Ambiente (CONAMA), em seu art. 3으, inciso II, constituía-se a APP "ao redor de nascentes ou olho d'água, ainda que intermitente, com raio mínimo de cinquenta metros de tal forma que proteja, em cada caso, a bacia hidrográfica contribuinte" (Brasil, 2002).

Em comparação com a Lei Florestal atual, verificou-se que a área situada no entorno de nascente ou olho d'água intermitente havia deixado de se ter exigência à sua proteção. Inclusive, áreas cobertas com vegetação nativa poderiam deixar de existir, por não apresentar "importância" sob o viés da conservação da água, uma vez que é interpretada como um ponto de brotamento de água inconstante e sem continuidade. Do ponto de vista dos ambientalistas, a sustentabilidade das alterações sofridas, de acordo com Faria et al. (2014), seria um possível retrocesso na legislação ambiental brasileira, reconhecida mundialmente como uma das mais desenvolvidas.

Entretanto, no primeiro trimestre do ano de 2018, o Supremo Tribunal Federal (STF) julgou as Ações Diretas de Inconstitucionalidade (ADIs), referentes à Nova Lei Florestal, e esta definição diferente do que era abordado pela Lei $\mathrm{n}^{\mathrm{o}}$ $4.771 / 1965$, que acarretava em desvantagens a proteção de olhos d'água, 
pois, o que seria intermitente, não era passível de ser protegido por uma APP, foi reconsiderada, fixando a interpretação de que os entornos das nascentes e dos olhos d'água intermitentes configuram área de preservação ambiental.

Caso não houvesse entendimento favorável à conservação dessas áreas, a pressão a esses locais provedores de água poderia trazer consequências negativas relevantes. Foi o caso de um estudo com propriedades rurais no Estado de São Paulo, em que Faria et al. (2014) apuraram em uma dessas propriedades, uma redução de cerca de $45 \%$ nas áreas de APP das nascentes intermitentes, uma vez que, anteriormente ao entendimento dado sobre as ADIs por parte do STF, essas partes da paisagem foram dispensadas da manutenção da APP em seu entorno.

A recuperação ou proteção da vegetação ciliar favorece o aumento da capacidade de armazenamento da água na microbacia ao longo da zona ripária e contribui para o aumento da vazão na estação seca do ano. Com isso, a destruição da mata ciliar, pode, a médio e longo prazo, por meio da degradação da zona ripária, diminuir a capacidade da microbacia para a manutenção da vazão, principalmente na estação seca (Zakia e Lima, 2004).

Com a nova Lei Florestal, a figura da APP foi mantida, porém em determinados imóveis a área mínima a ser recuperada foi modificada a partir do conceito de Áreas Rurais Consolidadas. Definidas como "área de imóvel rural com ocupação antrópica preexistente a 22 de julho de 2008, com edificações, benfeitorias ou atividades agrossilvipastoris, admitida, neste último caso, a adoção do regime de pousio" (Brasil, 2012). Para imóveis que possuem área rural consolidada, nem todas APPs terão áreas a serem recuperadas, pois é permitida a continuidade do uso em topos de morro, áreas de declividade maiores que $45^{\circ}$, chapadas, entre outros.

Restam a serem recuperadas áreas mínimas, apenas em APPs diretamente relacionadas a corpos d'água, como os casos de nascentes, veredas, cursos d'água, lagos e lagoas e reservatórios. Diminuiu-se claramente a proteção sobre as demais áreas, que protegem o solo e favorecem a recarga do lençol freático. Além de restringir a proteção, as faixas mínimas a serem recuperadas são menores e agora estão relacionadas ao tamanho dos imóveis, assim, propriedades de menor tamanho, recuperam faixas menores, o que ficou conhecido como "regra da escadinha" (Tabela 2). No fim, prevaleceu o conceito econômico do imóvel, ao favorecer os pequenos proprietários e não o ecológico, ao desconsiderar a função das áreas de proteção hídricas.

A área do imóvel é expressa em Módulos Fiscais (MFs). Laudares et al. (2017) explicaram o Módulo Fiscal como uma unidade de medida que considera para o seu cálculo: o tipo de exploração predominante no município; o produto proveniente dessa exploração; outras explorações existentes, mesmo que não sejam predominantes, mas que são significativas se consideradas a renda e área utilizada; além do conceito de propriedade familiar. 0 valor do módulo fiscal no Brasil varia de 5 a 110 ha, de acordo com o município onde a propriedade está localizada (Landau et al., 2012).

Nos casos de áreas rurais consolidadas em APP no entorno de nascentes e olhos d'água perenes, será admitida a manutenção de atividades agrossilvipastoris, de ecoturismo ou de turismo rural, sendo obrigatória a recomposição do raio mínimo de $15 \mathrm{~m}$, independente da dimensão da propriedade (Brasil, 2012). 
Tabela 2. Tamanhos mínimos para recomposição marginal de APP.

\begin{tabular}{lcc}
\hline APP & $\begin{array}{c}\text { Área do imóvel (Módulos } \\
\text { Fiscais) }\end{array}$ & $\begin{array}{c}\text { Faixas marginais para } \\
\text { recomposição em metros (m) }\end{array}$ \\
\hline \multirow{3}{*}{ Cursos d'água } & Até 1 & 5,0 \\
& Mais de 1 até 2 & 8,0 \\
& Mais de 2 até 4 & 15,0 \\
\hline Nascentes & Mais de 4 & 20,0 a 100,0 \\
\hline \multirow{3}{*}{ Lagos e lagoas } & Qualquer tamanho & 15 \\
& Até 1 & 5,0 \\
& Mais de 1 até 2 & 8,0 \\
Veredas & Mais de 2 até 4 & 15,0 \\
& Mais de 4 & 30,0 \\
\hline
\end{tabular}

Fonte: Brasil (2012).

Bonamigo et al. (2017) reiteraram que os proprietários rurais reconheceram que a nova lei introduziu métodos que eliminavam as incertezas legais experimentadas pela definição de APP. Cuppini et al. (2012) certificaram que a implantação da Lei no $12.727 / 2012$ proporcionou benefícios ao produtor rural, devido à possibilidade de ampliação da produção agropecuária. Além disso, ressalta-se que as APPs apresentam os solos mais férteis de uma bacia hidrográfica, favorecendo, portanto, o avanço das atividades agrícolas com a remoção da vegetação presente (Van-Den-Berg e Oliveira-Filho, 2000).

Segundo Tundisi (2014), o foco deveria ser o aumento de eficiência da produção agrícola e não o aumento da área plantada. Neste sentido, destaca-se os esforços das Organizações Não Governamentais (ONGs) em reação a maiores retrocessos para a legislação florestal.

Por outro lado, a modificação da legislação também está relacionada às alternativas de reduções de custos de recuperação de áreas para os pequenos produtores, além de ampliar para os mesmos as áreas produtivas, como supracitado. Contudo, essa mudança também foi importante para os grandes produtores agropecuários que diminuíram o passivo ambiental histórico no meio rural (Soares-Filho, 2014).

Comparando tamanhos mínimos de APP de nascentes em área comum e área consolidada, após a legitimação desse conceito, para imóveis com mais de dois e até quatro módulos fiscais, observa-se uma redução de $91 \%$ de área (Figura 1). Em consequência disso, é evidente que a composição de florestas nas paisagens agrícolas acompanhe $\mathrm{o}$ mesmo processo de redução das APPs, especialmente se for considerada a alteração do cômputo das áreas de RL, que podem estar sobrepostas a APP. De acordo com a SBPC (2011), esse cálculo não faz sentido em termos biológicos, pois, a RL e a APP possuem características, funções e serviços ecossistêmicos diferentes. 


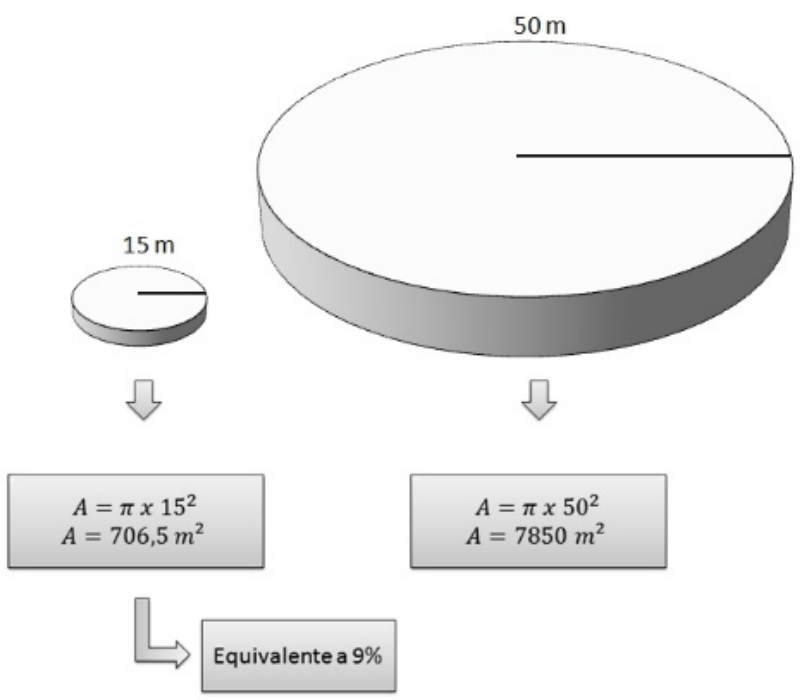

Figura 1. Representação da APP de nascente de área rural consolidada e área comum, respectivamente.

Observa-se que em APP de nascente, tanto $\mathrm{o}$ pequeno quanto $\mathrm{o}$ grande produtor tiveram o benefício da redução das áreas a serem recompostas. Rotta et al. (2017), estudando o impacto das mudanças das leis florestais na restauração florestal, encontraram resultados que corroboraram com as estimativas em larga escala de que tais mudanças, embora representem um ganho de área legalmente cultivável aos produtores rurais, reduzirão as áreas a serem restauradas e, como abordado por Metzger (2010), gerando impactos negativos à conservação da biodiversidade.

Um estudo de Borges et al. (2017) que trata da influência do tamanho do imóvel rural sobre as APPs de corpos d'água mostrou que os dados coletados corroboram com a política ambiental corrente, que trouxe flexibilizações aos pequenos proprietários e agricultores familiares, pois, o benefício da regra da escadinha irá abranger 95\% dos imóveis analisados. Soares-Filho et al. (2014) já haviam apontado que $90 \%$ das propriedades rurais brasileiras vão se beneficiar em razão da "regra da escadinha".

De fato, o ganho marginal para os proprietários das terras na redução da vegetação em APP, não exclusivamente de nascentes, pode resultar em um gigantesco ônus para a sociedade como um todo, especialmente, para a população urbana que mora naquela bacia ou região (SBPC, 2011).

A redução dos limites de APPs também foi mencionada por Bonamigo et al. (2017) quando esses admitiram existir mudanças significativas em termos de redução de superfície entre APP definida pelo antigo Código Florestal e áreas a serem recompostas nas APPs em áreas rurais consolidadas definidas pela Lei $\mathrm{n}^{0}$ 12.651/2012. Há projeções em grande escala, para a adequação à nova Lei Florestal, sobre a redução em $87 \%$ das áreas de restauração em topo de morro e em 58\% a área total destinada à restauração no Brasil (Soares-Filho et al., 2014).

Em razão das considerações da nova Lei Florestal serem direcionadas a diferentes faixas por tamanhos de 
imóveis, entende-se que tal fato poderá aumentar ainda mais a fragmentação da APP e, assim, dos ecossistemas existentes. Além disso, faixas estreitas possuem baixa efetividade, tendo visto que a maioria dos estudos relacionados a fluxo gênico de fauna aponta que estes corredores devem possuir no mínimo $50 \mathrm{~m}$ de largura para que muitos animais possam utiliza-los (Brancalion et al., 2010).

Nota-se que a fragmentação da APP, especialmente as de nascentes, incide em perda substancial da conservação desses ambientes, seja pelos prejuízos a conservação dos recursos genéticos da flora e fauna, seja pela redução de biomassa das áreas. Assim, como também apontado por Flynn et al. (2015), a conservação das fitofisionomias que são protegidas na APP é necessária para garantir o funcionamento e a provisão de serviços desses ambientes para as comunidades.

Desta forma, a manutenção de remanescentes de vegetação nativa nas propriedades e na paisagem, transcende seus benefícios ecológicos e permite vislumbrar, além do seu potencial econômico, a sustentabilidade da atividade agropecuária e a sua função social (SBPC, 2011).

\section{A importância de áreas protegidas como áreas de recarga para as nascentes}

A provisão de água de qualidade e em quantidade não está garantida apenas com esforço em se proteger unicamente APPs de cursos d'água. Outras áreas e unidades de paisagem, que contemplam outros tipos de APPs ou não, são também importantes para a manutenção da dinâmica dos recursos hídricos em uma bacia hidrográfica (Tamboril et al., 2015).

Outros locais na paisagem também exercem seu papel de proteção de recursos hídricos ou simplesmente pela manutenção do equilíbrio do ecossistema e seus ciclos. Destacam-se entre esses locais, por exemplo, os topos de morro, como áreas com aptidões de recarga dos lençóis freáticos, apresentando solos profundos $\mathrm{e}$ permeáveis, que favorecem os processos de retenção e infiltração. As florestas localizadas nas regiões mais elevadas são particularmente importantes ao garantirem condições de infiltração da água no solo e, consequente, recarga dos aquíferos (Lima et al., 2013).

Mais abaixo na paisagem, encontram-se as encostas de morros, com declividade mais acentuada, que são locais mais propensos a movimentos de massa. Tendem também a ter maior escoamento superficial, podendo gerar carreamento de sedimentos. Tambosi et al. (2015) reforçam a importância da presença de vegetação nas encostas pelo seu papel na interceptação das chuvas, proteção e estruturação do solo. Por isso, há também na legislação, mecanismo de proteção dessas áreas, desde que com declividade superior a $45^{\circ}$, equivalente a $100 \%$ (cem por cento) na linha de maior declive (Brasil, 2012).

Além dessa APP, a exigência RL, em propriedades ou posses rurais, é outro instrumento político mantido pela Lei $\mathrm{n}^{-}$12.651/2012 que auxilia para a proteção de zonas de recarga. Delimitada nos termos do art. 12, tem a função de assegurar o uso econômico de modo sustentável dos recursos naturais do imóvel rural, auxiliar a conservação e a reabilitação dos processos ecológicos e promover a conservação da biodiversidade, bem como o abrigo e a proteção de fauna silvestre e da flora nativa (Brasil, 2012).

Todos esses benefícios, de um modo ou de outro, implicam em resultados sobre a conservação da água. Entretanto, é importante evidenciar que a Lei no 12.651/2012, segundo Laudares et al. (2017), minimiza a proteção e compromete funções ambientais da APP e RL, especialmente, por permitir, em área de uso consolidado, uma gestão sustentável sob hiatos quanto aos tipos 
de atividades que poderiam ser sustentáveis.

Os tamanhos mínimos que devem compor a RL são descritos pela lei supracitada (Brasil, 2012), considerando-se a área da propriedade e variam entre os biomas. Aquelas propriedades localizadas na Amazônia Legal devem obedecer a porcentagem mínima de $80 \%$ da área total da propriedade, em área de florestas, 35\% para aquelas situadas em área de Cerrado e $20 \%$ àquelas que estão em Campos Gerais. Outros imóveis localizados nas demais regiões do país também devem seguir a proporção mínima de $20 \%$.

O texto da Lei no 12.651/2012 traz, em seu art. 14, alguns estudos e critérios que devem ser considerados para definir a localização da RL no imóvel rural e, um deles, é o plano da bacia hidrográfica, reforçando a participação dessa área nos serviços hidrológicos, embora não diretamente como a APP.

O uso dos ambientes em prol das necessidades humanas requer compreender as peculiaridades das áreas que, por sua vez, é uma das premissas do planejamento ambiental, usado como uma ferramenta essencial para o desenvolvimento sustentável, no intuito de maximizar impactos positivos aos sistemas naturais (Floriano, 2004). As ferramentas podem ser o Plano Diretor dos municípios, Planos de Manejo de Unidades de Conservação (UC) ou mesmo de RL, Plano de Bacias e, mais recentemente, o Cadastro Ambiental Rural.

O Plano Diretor está definido no Estatuto das Cidades (Brasil, 2001) como instrumento básico para orientar a política de desenvolvimento e de ordenamento da urbanização. Dusi e Bueno (2016) asseveram que no processo de elaboração do plano diretor e na fiscalização de sua implementação, os poderes legislativo e executivo municipais devem garantir a participação da população e de associações representativas dos vários segmentos da comunidade.

O Plano de Bacias constitui-se em diretrizes que visam fundamentar a implementação da Política Nacional de Recursos Hídricos. 0 manejo de bacias hidrográficas deve ser trabalhado de modo a garantir a quantidade $\mathrm{e}$ qualidade da água, especialmente em época seca, associado à questão financeira e de responsabilidade socioambiental. Portanto, Peres e Silva (2013), indicam que o manejo deve atender objetivos de gestão integrada, não apenas na dimensão ecológica, mas também nas dimensões social, cultural e política.

A crítica de Peres e Silva (2013) à relação desses dois planos, Diretor e de Bacias, consiste na efetividade da articulação entre esses dois instrumentos de planejamento e gestão, pois, segundo as autoras, a questão ambiental com foco nos recursos hídricos é abordada nos Planos Diretores em termos genéricos e, de maneira conflituosa quanto às competências para a gestão da água.

Entretanto, em uma perspectiva mais otimista, Schmitt et al. (2016) informam que políticas ligadas à gestão de bacias e microbacias hidrográficas vêm sendo adotadas no Brasil nas últimas décadas e os resultados obtidos demonstram a evolução da qualidade ambiental, aliados a processos produtivos mais adequados ao meio ambiente. Tundisi (2014) enfatiza que a integração entre ciência, tecnologia e desenvolvimento humano no nível de bacias hidrográficas é fundamental.

Para que se efetivassem os objetivos da Política Nacional de Recursos Hídricos (PNRH), foram propostos seis instrumentos, os planos de recursos hídricos, o enquadramento dos corpos de água, a outorga dos direitos de uso, a cobrança pelo uso de recursos hídricos; a compensação aos municípios e o sistema de informações (Peres e Silva, 2013). Estrategicamente, esses instrumentos devem contemplar metas, programas, projetos e diretrizes 
gerais que devem orientar o planejamento do uso dos recursos hídricos.

\section{Pagamentos de serviços ambientais na conservação de recursos hídricos}

As políticas de pagamentos por serviços ambientais têm se difundido como um instrumento econômico complementar às políticas de comando e controle. Considera-se o Pagamento por Serviços Ambientais (PSA) como uma ferramenta importante para a recuperação hidroambiental das bacias hidrográficas. Bonilla et al. (2016) abordaram as estratégias de PSA como um mecanismo baseado no mercado, que advém de respostas de políticas públicas para garantir a sustentabilidade dos serviços ecossistêmicos. Mas também, o PSA pode funcionar por outros mecanismos, como, por exemplo, incentivos públicos (Muradian et al., 2010).

Ressalta-se a importância dos incentivos a conservação das áreas de maior sensibilidade para os recursos hídricos, tamanha a dimensão da valorização da prestação dos seus serviços, seja pelo viés ambiental, econômico ou sociocultural (Tabela 3). Por isso os programas de PSA surgem como uma alternativa para a promoção da sustentabilidade nas suas mais diversas dimensões (Novaes, 2014).

Tabela 3. Objetivos identificados em iniciativas de PSA hídricos.

\begin{tabular}{|c|c|c|}
\hline $\begin{array}{c}\text { Relacionados aos serviços } \\
\text { ambientais hídricos }\end{array}$ & $\begin{array}{c}\text { Relacionados aos serviços } \\
\text { socioeconômicos }\end{array}$ & $\begin{array}{l}\text { Relacionados a outros } \\
\text { serviços ambientais }\end{array}$ \\
\hline $\begin{array}{l}\text { Controlar poluição da água. } \\
\text { Melhorar a qualidade da água. } \\
\text { Favorecer a infiltração de água } \\
\text { no solo. } \\
\text { Controlar o transporte de } \\
\text { sedimentos. } \\
\text { Regular o fluxo hídrico. } \\
\text { Favorecer a recarga de } \\
\text { aquíferos. } \\
\text { Proteger nascentes. } \\
\text { Proteger APP. } \\
\text { Adotar medidas para } \\
\text { conservação de bacias } \\
\text { hidrográficas. }\end{array}$ & $\begin{array}{l}\text { Reduzir a pobreza. } \\
\text { Fortalecer as populações rurais. } \\
\text { Melhorar a qualidade de vida. } \\
\text { Valorizar e fortalecer a } \\
\text { participação de diferentes } \\
\text { grupos sociais e culturais. } \\
\text { Fortalecer a igualdade de } \\
\text { gênero. }\end{array}$ & $\begin{array}{l}\text { Reduzir desmatamento. } \\
\text { Manter a vegetação natural. } \\
\text { Conservar a biodiversidade. } \\
\text { Conservar habitats. } \\
\text { Preservar espécies } \\
\text { ameaçadas. } \\
\text { Reduzir emissões de gases de } \\
\text { efeito estufa (GEE). } \\
\text { Manter beleza cênica. }\end{array}$ \\
\hline
\end{tabular}

Fonte: Adaptado de Gjorup et al. (2016).

É evidente, como dito por Jardim e Bursztyn (2015), que o benefício é coletivo, mas os custos da conservação são exclusivos dos produtores rurais, quando os esforços pela seguridade hídrica acontecem no meio rural. Para essas autoras, o PSA viabiliza o processo da conservação ambiental, ao dividir com os beneficiários dos serviços ambientais os custos de execução das ações conservacionistas praticadas pelos provedores.

Novaes (2014), em um levantamento sobre Programas e Políticas de Pagamento por Serviços Ambientais (PPPSA) em atividade no Brasil, observou que $75 \%$ daqueles com foco em água, ou seja, PSA hídricos, com 
relação ao uso da terra, eram voltados para conservação e recuperação de cobertura vegetal nativa.

Projetos de PSA são propostos com o princípio de que ao realizar um bom manejo de uma bacia hidrográfica, inclusive com intervenções de restauração em benefício da conservação, considerando que a bacia sempre está em um estado de equilíbrio transacional, serão gerados serviços ambientais de qualidade. 0 bom manejo além de incidir resultados sobre a gestão da água, também pode agir na gestão do uso e ocupação do solo, que terá influência direta sobre a provisão desses serviços (Peres e Silva, 2013).

A "Crise Hídrica" da Região Sudeste do Brasil, principalmente no Estado de São Paulo, onde está localizado o Sistema Cantareira, foi considerada a pior em 80 anos e afetou intensamente a vida de cerca de 20 milhões de habitantes da Região Metropolitana de São Paulo (Targa e Batista, 2015). Este recurso, que se acreditava por muito tempo ser inesgotável, tem perdido sua qualidade e quantidade com o passar dos tempos.

Alguns dos principais fatores que levaram à redução dos níveis dos reservatórios foram: o período chuvoso entre 2013 e 2014, que foi atipicamente seco; o aumento efetivo do consumo e desperdício de água pela população; a alteração do uso do solo nas APPs; a erosão e o assoreamento dos cursos d'água; a falta de planejamento e a má gestão dos recursos hídricos (Silva et al., 2017; Coelho et al., 2016; Targa e Batista, 2015).

0 uso do PSA demonstra a importância do envolvimento dos usuários e produtores de serviços ambientais no âmbito da gestão integrada dos recursos hídricos, pois, sem um bom conhecimento da causa e efeito, não há como reconhecer os reais prestadores de serviços ambientais as comunidades (Fidalgo et al., 2017).

O Brasil apresenta experiências sobre PSA desde 2000, com o programa
"Proambiente" e a partir de 2001, a Agência Nacional das Águas (ANA) desenvolveu o Programa Produtor de Água, a primeira iniciativa de PSA hídrico no Brasil (Bonilla et al., 2016). Távora et al. (2018) expuseram que os programas de PSA no Brasil têm sido desenvolvidos, principalmente, no bioma Mata Atlântica e estão relacionados com a produção de recursos hídricos. Os mesmos autores destacaram que os programas de PSA hídricos têm ganhado cada vez mais estímulo, primeiramente, porque a proteção desses serviços garante o abastecimento das áreas urbanas.

Guedes e Seehusen (2011) reiteraram que a ANA teve um papel chave ao desenvolver o conceito denominado "Produtor de Água", que reconhece o papel de geração de serviços ambientais desempenhado por produtores rurais no abatimento de erosão e infiltração de água, a partir do desenvolvimento de práticas de conservação do solo e práticas de conservação e restauração florestal.

Um exemplo pioneiro de PSA hídrico é o projeto Conservador das Águas, em Extrema, Minas Gerais. A subbacia dos rios Jaguari e Jacareí, que corta a região de Extrema, é responsável por $22 \mathrm{~m}^{3} / \mathrm{s}$ dos $33 \mathrm{~m}^{3} / \mathrm{s}$ de água destinados ao abastecimento da Região Metropolitana de São Paulo, por meio do Sistema Cantareira (Lamim-Guedes et al., 2017).

Estrategicamente, as ações de monitoramento das iniciativas de PSA possibilitam insuspeição, desencadeando vontades políticas para a implementação de novos projetos. Fidalgo et al. (2017) asseguram que à medida que mais iniciativas de PSA sejam monitoradas e os resultados dos seus impactos nos serviços ecossistêmicos e bem-estar da população envolvida sejam comprovados, o monitoramento poderá ser simplificado, reduzindo-se custos e esforços.

Contemporaneamente, apesar dos esforços de implantação de alguns projetos de PSA no Brasil, o 
direcionamento federal vai à orientação contrária. As mudanças permitidas pela Lei no $12.651 / 2012$, incidirão em menor área a ser recuperada, o que poderá ocasionar em menor área de recarga e proteção das nascentes, diminuindo o potencial para o abastecimento hídrico da sociedade.

Em vista disso, é interessante que os resultados sejam amplamente difundidos, especialmente para aqueles que estão pagando pelo PSA. Logo, métodos robustos de seleção de áreas prioritárias a intervenção e de monitoramento que gerem evidências quantificáveis sobre o impacto desses projetos são fundamentais para $o$ estabelecimento de sua sustentabilidade no longo prazo (Fidalgo et al., 2017).

\section{Considerações finais}

As alterações promovidas pela Lei $\mathrm{n}^{\mathrm{o}}$ 12.651/2012 permitiram que áreas protegidas, distribuídas na paisagem, em diferentes posições de relevo, obtivessem redução em suas extensões, comprometendo assim as iniciativas de conservação da natureza, sejam por políticas públicas anteriores a essa lei, ou por planejamentos individuais de proprietários de terra. Com isso, entende-se que se reduzindo essas áreas, terá-se o impacto direto na produção de água e, consequentemente, nos serviços ambientais das nascentes, pois, áreas importantes de recarga de água, poderão ser afetadas negativamente, trazendo prejuízos ao provimento e disponibilidade dos recursos hídricos às comunidades. $\mathrm{E}$ consequentemente, provisão de água a população.

Neste cenário, sob as perspectivas das estimativas do crescimento populacional, que expõem aumento acentuado do número de habitantes, alterações na legislação dessa natureza contribuem para a intensificação dos problemas relativos à escassez de recursos, como a crise hídrica dos últimos anos. Esse direcionamento, contrário às necessidades de estímulos à proteção e conservação de áreas, principalmente aquelas de maior sensibilidade hidrológica, pode manifestar o aumento de conflitos socioambientais que se originam de múltiplas fontes $\mathrm{e}$ incidem sobre a qualidade de vida do homem.

Por isso, a decisão de proteger a paisagem e garantir o provimento de serviços ambientais, como a disponibilidade de recursos hídricos em quantidade e qualidade, podendo ser por implantação de programas de pagamento de serviços ambientais, é, além de tudo, uma escolha ética e de justiça social, tendo em vista que as perdas desses serviços afetarão, de maneira distinta, os grupos da sociedade, reproduzindo desigualdades sociais já predominantes.

Por conseguinte, é primordial que se fomentem ainda mais as articulações que tencionem as esferas administrativas do poder público e a sociedade civil, no intuito da garantia da segurança hídrica na interface com a conservação da biodiversidade, saneamento e produção de alimentos.

\section{Conflito de interesses}

Os autores declaram não haver conflito de interesses.

\section{Referências}

Arantes, T.; Faria, R.; Souza, L.; Botelho, S.; Guimarães, J. Avaliação da regeneração natural como processo de recuperação do entorno de nascente perturbada. Enciclopédia Biosfera, v. 8, n. 14, p. 10191041, 2012. Disponível em: <http://www.conhecer.org.br/enciclop/201 2a/ambientais/avaliacao da regeneracao.pdf>. Acesso em: 24 jan. 2018.

Baker, T. J.; Miller, S. N. Using the Soil and Water Assessment Tool (SWAT) to assess land use impact on water resources in an East African watershed. Journal of Hydrology, v. 486, p. 100-111, 2013. https://doi.org/10.1016/j.jhydrol.2013.01.0 41 
Bonamigo, A.; Schimalski, M. B.; Soares, P. R. C.; Liesenberg, V.; Souza, T. R. D.; Boesing, T. L. S. Changes in permanent preservation areas in rural properties of the Santa Catarina State Southern plateau according to the laws No. 4,771 and 12,651. Ciência Rural, v. 47, n. 2, e20160489, 2017. https://doi.org/10.1590/0103-8478cr20160 489

Bonilla, D. A. T.; Queiroz L. S.; Meireles, A. J. Serviços ecossistêmicos ou ambientais? Implicações na Política Nacional de Pagamento por Serviços Ambientais no Brasil. Revista Brasileira de Educação Ambiental, v. 11, n. 4, Anais do V CBEAAGT, p. 298-316, 2016. Disponível em: <http://www.sbecotur.org.br/revbea/index. php/revbea/article/view/5038/3176>. Acesso em: 24 jan. 2018.

Borges, L. A. C. Aspectos técnicos e legais que fundamentam o estabelecimento das áreas de preservação permanente (APP). Lavras: Universidade Federal de Lavras, 2008. (Tese de doutorado).

Borges, L. A. C.; Moras Filho, L. O.; Marques, R. T.; Silva, C. C.; Paula Silva, L. G. A influência do tamanho do imóvel rural sobre as áreas de preservação permanente de corpos d'água. Caminhos de Geografia, v. 18, n. 64, p. 444453, 2017. https://doi.org/10.14393/ RCG186433

Borges, L. A. C.; Rezende, J. L. P. Áreas protegidas no Interior de propriedades rurais: a questão das APP e RL. Floresta e Ambiente, v. 18, p. 210-222, 2011. https://doi.org/10.4322/floram.2011.040

Brancalion, P. H. S.; Ribeiro Rodrigues, R.; Gandolfi, S.; Yoshio Kageyama, P.; Nave, A. G.; Bertin Gandara, F.; Tabarelli, M. Instrumentos legais podem contribuir para a restauração de florestastropicais biodiversas. Revista $\begin{array}{llll}\text { Árvore, } & \text { v. } 34, & \text { n. 3, } & \text { p. 455-470, } 2010 .\end{array}$ https://doi.org/10.1590/S0100-67622010 000300010

Brasil. Resolução CONAMA no 303 , de 20 de março de 2002. Dispõe sobre parâmetros, definições e limites de Áreas de Preservação Permanente. Disponível em: <http://www.mma.gov.br/port/conama/res /res02/res30302.html>. Acesso em: 24 jan. 2018.

Brasil. Constituição da República Federativa do Brasil de 1988. Disponível em: <http://www.planalto.gov.br/ccivil_03/ constituicao/constituicao.htm>. Acesso em: 24 jan. 2018.

Brasil. Decreto no 23.793, de 23 de janeiro de 1934. Approva o codigo florestal que com este baixa. Disponível em: <http://www.planalto.gov.br/Ccivil_03/decr eto/1930-1949/D23793impressao.htm>.

Acesso em: 24 jan. 2018.

Brasil. Lei no 4.771, de 15 de setembro de 1965. Institui o novo Código Florestal. Disponível em: <http://www.planalto.gov. br/Ccivil_03/LEISL4771impressao.htm>.

Acesso em: 24 jan. 2018.

Brasil. Lei no 9.433, de 8 de janeiro de 1997. Institui a Política Nacional de Recursos Hídricos, cria o Sistema Nacional de Gerenciamento de Recursos Hídricos, regulamenta o inciso XIX do art. 21 da Constituição Federal, e altera o art. $1^{\circ}$ da Lei no 8.001, de 13 de março de 1990, que modificou a Lei no 7.990 , de 28 de dezembro de 1989. Disponível em: <http://www.planalto.gov.br/ccivil_03/Leis/ L9433.htm>. Acesso em: 24 jan. 2018.

Brasil. Lei no 10.257, de 10 de julho de 2001. Regulamenta os arts. 182 e 183 da Constituição Federal, estabelece diretrizes gerais da política urbana e dá outras providências. Disponível em: <http://www.planalto.gov.br/Ccivil_03/leis/ LEIS_2001/L10257.htm>. Acesso em: 24 jan. 2018.

Brasil. Lei no 12.651, de 25 de maio de 2012. Dispõe sobre a proteção da vegetação nativa; altera as Leis $\mathrm{n}^{\text {os }} 6.938$, de 31 de agosto de 1981, 9.393, de 19 de dezembro de 1996, e 11.428, de 22 de dezembro de 2006; revoga as Leis $n^{\text {os }} 4.771$, de 15 de setembro de 1965, e 7.754, de 14 de abril de 1989, e a Medida Provisória no 2.166-67, de 24 de agosto de 2001; e dá outras providências. Disponível em: <http://www.planalto.gov. br/cciviL_03/_Ato2011-2014/2012/Lei/ L12651 compilado.htm>. Acesso em: 24 jan. 2018.

Castro, P. S.; Gomes, M. A. Técnicas de conservação de nascentes. Ação Ambiental, v. 4, n. 20, p. 24-26, 2001.

Coelho, C. A. S.; Oliveira, C. P.; Ambrizzi, T.; Reboita, M. S.; Carpenedo, C. B.; Campos, J. L. P. S.; Tomaziello, A. C. N.; Pampuch, L. A.; Custodio, M. S.; Dutra, L. M M.; Rocha, R. P.; Rehbein, A. The 2014 Southeast Brazil austral summer drought: regional scale 63 mechanisms and teleconnections. Climate 
Dynamics, v. 46, n. 11, p. 3737-3752, 2016. https://doi.org/10.1007/s00382-015-2800-1

Cuppini, D.; Decian, V.; Rovani, I.; Quadros, F. R.; Zotti, N. Análise das áreas de preservação permanente em uma propriedade rural sob o enfoque do Código Florestal Federal (Brasil 1965) e Lei $12.727 / 2012$. Perspectiva, v. 36, n. 135, p.41-45, 2012. Disponível em: <http://www.uricer.edu.br/site/pdfs/perspe ctiva/135_288.pdf>. Acesso em: 24 jan. 2018.

Davis, S. N.; Dewiest, R. J. Hydrogeology. New York: John Wiley \& Sons, 1966.

Dusi, L.; Bueno, L.S. B. O planejamento em áreas protegidas por seu valor ambiental e as ferramentas de gestão. Ignis, v. 5, n. 2, p. 44-61, 2016. Disponível em: $<$ https://periodicos.uniarp.edu.br/ignis/arti cle/view/1122/532>. Acesso em: 24 jan. 2018.

Faria, L. C.; Adriano Júnior, F. C.; Tonello, K. C.; Valente, R. O. A. Reflexos das alterações no Código Florestal Brasileiro em Áreas de Preservação Permanentes de duas propriedades rurais em Itu e Sarapuí, SP. Revista Ambiente \& Água, v. 9, n. 3, p. 559568, 2014. https://doi.org/10.4136/ambiagua.1354

Felippe, M. F.; Magalhães Junior, A. P.; Pesciotti, H.; Coeli, L. Nascentes antropogênicas: processos tecnogênicos e consequências hidrogeomorfológicas em meio urbano. Revista Brasileira de Geomorfologia, v. 14, n. 4, p. 279-286, 2013. https://doi.org/10.20502/rbg.v14i4.210

Fidalgo, E.; Prado, R.; Turetta, A.; Schuler, A. Manual para pagamento por serviços ambientais hídricos: seleção de áreas e monitoramento. Brasília: Embrapa, 2017.

Fisher, L. R. C.; Sá, J. D. M. Estatuto da Cidade e a Resolução Conama no 369/2006. Anais do Seminário sobre tratamento de áreas de preservação permanente em meio urbano e restrições ambientais o parcelamento do solo, São Paulo, FAUUSP, 2007.

Floriano, E. P. Planejamento ambiental. 1. ed. Santa Rosa: ANORGS, 2004. (Caderno Didático, 6).

Flynn, M. N.; Louro, M. P.; Mendes, M. S. P.; Gonzalez, R. C. Relações ecológicas entre fauna e flora das áreas de preservação permanente (APP) do Médio e Alto Tietê. Revista Intertox de Toxicologia, Risco Ambiental e Sociedade, v. 8, n. 2, p. 38-93, 2015. https://doi.org/10.22280/revintervol 8ed2.202
Gjorup, A. F.; Fidalgo, E. C. C.; Prado, R. B.; Schuler, A. E. Análise de procedimentos para seleção de áreas prioritárias em Programas de Pagamento por Serviços Ambientais Hídricos. Revista Ambiente \& Água, v. 11, n. 1 , p. 225-238, 2016. https://doi.org/ 10.4136/ambi-agua.1782

Guedes, F. B.; Seehusen, S. E. Pagamentos por serviços ambientais na Mata Atlântica: lições aprendidas e desafios. Brasília: MMA, 2011.

Guerra, A. T; Guerra, A. J. T. Novo Dicionário Geológico-Geomorfológico. Rio de Janeiro: Bertrand Brasil, 2009.

Jardim, M. H.; Bursztyn, M. A. Pagamento por serviços ambientais na gestão de recursos hídricos: o caso de Extrema (MG). Engenharia Sanitaria e Ambiental, v. 20, n. 3, p. 353-360, 2015. https://doi.org/ 10.1590/S1413-41522015020000106299

Kresic, N.; Stevanovic, Z. Groundwater hydrology of springs: Engineering, theory, management and sustainability. Oxford: Butterworth-Heinemann, 2009.

Lamim-Guedes, V.; Ferreira, L.; Carvalho, P. P.; Camargo, P. L. T. Pagamento por serviços ambientais como instrumento para políticas públicas de conservação ambiental. InterfacEHS, v. 12, n. 1, p. 1-17, 2017. Disponível em: <http://www3.sp.senac.br/ hotsites/blogs/InterfacEHS/wp-content/ uploads/2017/06/1-182_InterfacEHS_Artigo Revisado.pdf>. Acesso em: 24 jan. 2018.

Landau, E. C.; Cruz, R. K.; Hirsch, A.; Pimenta, F. M.; Guimarães, D. P. Variação geográfica do tamanho dos módulos fiscais no Brasil. Sete Lagoas: Embrapa Milho e Sorgo, 2012.

Lapola, D. M.; Martinelli, L. A.; Peres, C. A.; Ometto, J. P. H. B.; Ferreira, M. E.; Nobre, C. A.; Aguiar, A. P. D.; Bustamante, M. M. C.; Cardoso, M. F.; Costa, M. H.; Joly, C. A.; Leite, C. C.; Moutinho, P.; Sampaio, G.; Strassburg, B. B. N.; Vieira, I. C. G. Pervasive transition of the Brazilian land-use system. Nature Climate Change, v. 4, p. 27-35, 2014. https://doi.org/ $10.1038 /$ nclimate 2056

Laudares, S. S. D. A.; Borges, L. A. C.; Ávila, P. A. D.; Oliveira, A. L. D.; Silva, K. G. D.; Laudares, D. C. D. A. Agroforestry as a sustainable alternative for environmental regularization of rural consolidated occupations. Cerne, v. 23, n. 2, p. 161 174, 2017. https://doi.org/10.1590/0104776020 1723022240 
Leitão, R. P.; Zuanon, J.; Mouillot, D.; Leal, C. G.; Hughes, R. M.; Kaufmann, P. R.; Villéger, S.; Pompeu, P. S.; Kasper, D.; Paula, F. R.; Ferraz, S. F. B.; Gardner, T. A. Disentangling the pathways of land use impacts on the functional structure of fish assemblages in Amazon streams. Ecography, v. 41, n. 1, p. 219-232, 2017. https://doi.org/10.1111/ ecog.02845

Lima, W. D. P.; Ferraz, S. D. B.; Ferraz, K. M. P. M. Interações bióticas e abióticas na paisagem: uma perspectiva eco-hidrológica. In: Calijuri, M. C.; Cunha, D. G. F. (Ed.). Engenharia ambiental: conceitos, tecnologia e gestão. Rio de Janeiro: Elsevier, 2013. p. 215-244.

Machado, P.A. L. Direito ambiental brasileiro. 12. ed. São Paulo: Malheiros, 2004.

Magalhães, J.P. Evolução do direito ambiental no Brasil. São Paulo: J. Oliveira, 2002.

Medeiros, R. Evolução das tipologias e categorias de áreas protegidas no Brasil. Ambiente \& Sociedade, v. 9, n. 1, p. 41-64, 2006. https://doi.org/10.1590/S1414753X2006000100003

Metzger, J. P. O Código Florestal tem base científica? Conservação e Natureza, v. 8, n. 1, p. 1-5, 2010. Disponível em: <http://ecologia.ib.usp.br/lepac/codigo_flore stal/Metzger_N\&C_2010.pdf>. Acesso em: 24 jan. 2018.

Muradian, R.; Corbera, E.; Pascual, U.; Kosoy, N.; May, P. H. Reconciling theory and practice: An alternative conceptual framework for understanding payments for environmental services. Ecological Economics, v. 69, n. 6, p. 1202-1208, 2010. https://doi.org/ 10.1016/j.ecolecon.2009.11.006

Novaes, R. M. L. Monitoramento em programas e políticas de pagamentos por serviços ambientais em atividade no Brasil. Estudos Sociedade e Agricultura, v. 22, n. 2, p. 408-431, 2014. Disponível em: <https://ainfo.cnptia.embrapa.br/digital/bit stream/item/117584/1/2014AP36.pdf>. Acesso em: 24 jan. 2018.

Pereira, C. R.; Valcarcel, R.; Silva Barbosa, R. Quantificação da chuva oculta na Serra do Mar, Estado do Rio de Janeiro. Ciência Florestal, v. 26, n. 4, p. 1061-1073, 2016. https://doi.org/10.5902/1980509824995

Peres, R. B.; Silva, R. S. Análise das relações entre o Plano de Bacia Hidrográfica Tietê-
Jacaré e os Planos Diretores Municipais de Araraquara, Bauru e São Carlos, SP: avanços e desafios visando à integração de instrumentos de gestão. Sociedade \& Natureza, v. 25, n. 2, p. 349-362, 2013. https://doi.org/10.1590/S1982-4513201 3000200011

Pinto, L. V. A.; Roma, T. D.; Balieiro, K. R. C. Avaliação qualitativa da água de nascentes com diferentes usos do solo em seu entorno. Cerne, v. 18, n. 3, p. 495-505, 2012. https://doi.org/10.1590/S0104-77602012 000300018

Queiroz, M. L. Nascentes, veredas e áreas úmidas: revisão conceitual e metodologia de caracterização e determinação: estudo de caso na Estação Ecológica de Águas Emendadas - Distrito Federal. Brasília: Universidade de Brasília, 2015. (Dissertação de mestrado).

Rodrigues-Filho, J. L.; Degani, R. M.; Soares, F. S.; Periotto, N. A.; Blanco, F. P.; Abe, D. S.; Tundisi, J. G. Alterations in land uses based on amendments to the Brazilian Forest Law and their influences on water quality of a watershed. Brazilian Journal of Biology, v. 75 , n. 1, p. 125-134, 2015. https://doi.org/ 10.1590/1519-6984.08813

Rotta, L.; Viani, R. A. G.; Rosário, V. Mudanças nas leis florestais e o impacto na restauração florestal e conectividade na paisagem. Revista Ciência Tecnologia \& Ambiente, v. 4 , n. 1 , p. $12-19,2017$. https://doi.org/ 10.4322/2359-6643.04104

SBPC - Sociedade Brasileira para o Progresso da Ciência Academia Brasileira de Ciências. 0 Código Florestal e a Ciência: contribuições para o diálogo. São Paulo: SBPC, 2011.

Schmitt, A. L.; Ricce, W. S.; Braga, H. J.; Zamparetti, A. F.; Vieira, V. F. Proposta de zoneamento ambiental aplicado à Microbacia do Rio Vargem dos Pinheiros, Angelina, Santa Catarina, Sul do Brasil. Revista Gestão \& Sustentabilidade Ambiental, v. 5, n. 1, p. 411-434, 2016. https://doi.org/10.19177/ rgsa.v5e12016411-434

Silva, M. P. S.; Barbosa, T. R. L.; Barroso, D. G. Preservação de Nascentes. Niteroi: Superintendência de Desenvolvimento Sustentável, 2008. (Programa Rio Rural, Manual Técnico, 8). Disponível em: <http://www.pesagro.rj.gov.br/downloads/r iorural/08 Preservacao de Nascentes.pdf $>$. Acesso em: 24 jan. 2018. 
Soares-Filho, B. S. Impacto da revisão do Código Florestal: como viabilizar o grande desafio adiante? Brasília: Secretaria de Assuntos Estratégicos, 2014.

Tambosi, L. R.; Vidal, M. M.; Ferraz, S. F. D. B.; Metzger, J. P. Funções eco-hidrológicas das florestas nativas e o Código Florestal. Estudos Avançados, v. 29, n. 84, p. 151-162, $2015 . \quad$ https://doi.org/10.1590/S010340142015000200010

Targa, M. S.; Batista, G. T. Benefits and legacy of the water crisis in Brazil. Revista Ambiente \& Água, v. 10, n. 2, p. 234-239, 2015. https://doi.org/ 10.4136/ambiagua.1629

Távora, G. S. G.; Silva, A. S.; Turetta, A. P. D. Análise da política por pagamento por serviços ambientais como um instrumento para sustentabilidade socioambiental. Geosul, v. 33, n. 66, p. 29-47, 2018. https://doi.org/10.5007/2177-5230.2018 v33n66p29
Tundisi, J. G. Recursos hídricos no Brasil: problemas, desafios e estratégias para 0 futuro. Rio de Janeiro: Academia Brasileira de Ciências, 2014.

Tundisi, J. G.; Matsumura-Tundisi, T. Limnologia. São Paulo: Oficina de Textos, 2008.

Tundisi, J. G.; Matsumura-Tundisi, T. Recursos hídricos no século XXI. São Paulo: Oficina de Textos, 2011.

Van-Den-Berg, E.; Oliveira-Filho, A. T. Composição florística e estrutura fitossociológica de uma floresta ripária em Itutinga, MG, e comparação com outras áreas. Brazilian Journal of Botany, v. 23, n. 3, p. 231-253, 2000. https://doi.org/10.1590/ S0100-84042000000300002

Zakia, M. J. B.; Lima, W. P. Hidrologia de matas ciliares. In: Rodrigues, R. R.; Leitão Filho, H. Matas Ciliares: conservação e recuperação. São Paulo: EDUSP, 2004. p. 33-44. 